\title{
Maternal oxygen inhalation therapy for intrauterine fetal resuscitation
}

\author{
Yunhai Chuai ${ }^{1}$, Wen Jiang ${ }^{1}$, and Lei Chen ${ }^{1}$ \\ ${ }^{1}$ Chinese PLA General Hospital
}

June 25, 2020

\begin{abstract}
Maternal oxygen (O2) inhalation therapy is widely used for intrauterine fetal resuscitation. However, the research results were inconsistent in the effects of maternal $\mathrm{O} 2$ administration on fetal oxygenation. There were only four randomized controlled trials (RCTs) of O2 inhalation during labor showed that $\mathrm{O} 2$ inhalation therapy did not improve the fetal acid-base metabolism state or even increased the risk of fetal acidosis. Several studies showed that O2 inhalation therapy triggered maternal-fetal oxidative stress, and several studies found hyperoxia-induced vasoconstriction. This article reviewed the controversy of maternal $\mathrm{O} 2$ administration on mother and fetus during labor.
\end{abstract}

\section{Hosted file}

manuscript.doc available at https://authorea.com/users/336660/articles/462327-maternaloxygen-inhalation-therapy-for-intrauterine-fetal-resuscitation 